\title{
The Effects of Gap Disturbance on the Seedling Emergence, Survival and Growth of Two Different Native Species in Inner Mongolia
}

\author{
KAN Haiming ${ }^{1,}$ a , WU Juying ${ }^{1, b}$,SUN Tiejun ${ }^{1, c}$, LIU Guixia ${ }^{2, d}$, PANG Zhuo ${ }^{1, e}$
}

${ }^{1}$ Beijing Research \& Development Center of Grass and Environment,Beijing Academy of Agriculture and Forestry Sciences, Beijing 100097, China; ${ }^{2}$ College of life science, Hebei University,Baoding,China

corresponding author:akanhaiming@hotmail.com, bwujuying@263.net.

'stj_cau@163.com, ${ }^{\mathrm{d}}$ liuguixia1971@163.com, ${ }^{\mathrm{p} p a n g z h-84 @ 163 . c o m ~}$

Key words: reseeding management, restoration ecology, gap disturbance, gap size

Abstract:A field study was conducted to investigate the effects of gap disturbance on the seedling establishment process of two native species. Seeds of Agropyron cristatumandStipa kryloviiwere reseeded to artificially created gaps in a degraded steppe in North China. There were seven treatments: shoot gaps and root gaps $(10 \mathrm{~cm}, 20 \mathrm{~cm}$ and $40 \mathrm{~cm}$ in diameters), no gaps (control). Shoot gaps were formed by removing above ground vegetation and below ground biomass without restricting the re-growth of neighbor roots back into the gap. The root gaps were accomplished by using polyvinyl chloride pipes sunk in the soil of shoot gaps to exclude neighboring roots. Seedling emergence, survival and growth performance after 90 days of growing were recorded for both species. Gap disturbance significantly increased soil moisture, especially for root gaps.Gap size significantly promoted seedling emergence. Emergence increased for both species as gap size increased.Seedling emergence and survivorship of both species were greater in gaps than in controls.However, the gap size showed a significantly negative effect onAgropyron cristatum's survivorship.Gaptreatments had positive effects on seedling growth(including seedling height, dry weight, and numbers of tillers andleaves) of Stipa krylovii, but had negative effects on seedling growth ofAgropyron cristatum.Predation by insects may be one of the key reasons to explain the stand dominance in this grassland.The results implythat we should take different coping strategies with different species in the process of restoration by reseeding native species.

\section{Introduction}

Restoration of semi-natural grassland communities involves a combination of sward disturbance to create a temporal window for establishment and target species introduction, the latter usually accomplished by seed sowing[1].Disturbance is an important factor in maintaining species richness in plant communities[2].It operates on adult plants by providing regeneration niches for recruitmentif it has greater relative impact on dominant species [1, 3, 4].Gap creation has been shown by many authors to be a key requirement for diversity maintenance in grassland communities[5] and necessary for successful seedling establishment of many species[6], as many species are limited by microsite [7], seed [8].Gaps providean opportunity for regeneration from seed alreadypresent in the seed bank, existing vegetation, or byintroduction from outside the site. This is true not only for guilds of annuals and biennials[7], but also for the replacement of perennials[9].

Both Agropyron cristatumandStipakryloviihave the same photosynthetic pathway and are resistant to drought.They are native perennial grasses with good palatability and high forage value in northern China, especially in the Inner-Mongolia steppe [10]. In the eastern parts of typical steppes of Inner Mongolia, Stipa kryloviiis often a sub-dominant species with Leymus chinensis dominant, and Agropyron cristatum is mostly a companion species in a semi-arid grassland community[10, 11]. However, nearly $86 \%$ of these grasslands are facing degradation or have been degraded in recent decades due to excess reclamation and overgrazing. Climate change and human activities have amplified the magnitude of these disturbance events[12].To understand the implications of these disturbance conditions for community structure and stability, the conceptualization of "gap disturbance" seems necessary. Studies on the effects of gaps in Stipa kryovii and Agropyron 
cristatum seedling establishment can give a better understanding of restoration mechanisms for degraded steppe of Inner Mongolia and will also provide knowledge for the gap disturbance theory.

\section{Materials and methods}

The experiment was carried out in the Grassland Vegetation Restoration and Reconstruction Key Laboratory of China, Ministry ofAgriculture Experiment Station $\left(41^{\circ} 52^{\prime} \mathrm{N}, 115^{\circ} 50^{\prime} \mathrm{E}\right.$, altitude $1370 \mathrm{~m})$, Saibei administrative region, Hebei province, China. The experiment was conducted in a split-plot design, and in each plot a randomized block design was used. The main plots consist of two different species separately(Agropyron cristatum, Stipa krylovii). We refer to a gap with the presence of neighboring roots and loss of photosynthetic biomass as a "canopy gap," or we can call it "shoot gap," and a shoot gap with neighboring roots excluded as a "root gap"[6].There wereseventreatments randomized in each of eight replicate blocks in one plot.The treatments were no gap (control), and shoot and root gaps each with diameters of 10, 20 and $40 \mathrm{~cm}$.Before the experiment started, shoot gaps were created by the removal of both above- and below-ground biomass without any restriction to the neighbor roots re-growth into the gap, and root gaps were created by using a cylindrical PVC pipe to restrict neighbor roots re-growth into the gaps.

Ten seeds of each species were sown into the center $(8 \mathrm{~cm}$ in diameter $)$ of each gap or under the intact canopy for the control at a depth of $2 \mathrm{~cm}$. The number of emerging seedlings was recorded daily and identified with colored markers untilno new seedlings emerged. For all the surviving seedlings, five replicates of each treatmentwere randomly chosen, cut at the soil surface, then dried at $80^{\circ} \mathrm{C}$ for $48 \mathrm{~h}$ and weighed. The experiment was performed in an enclosure to prevent damage to seedlings from trampling or grazing by domestic livestock.

Soil temperature and moisture were measured at 5-cm weekly after the cessation of watering, by using a Moisture Meter-HH2 (Delta-T Devices Ltd.) with a wet senor WET-2 (Delta-T Devices Ltd.)

\section{Results and Discussions}

Emergence was observed in all gaps within 2 weeks after sowing the seeds, and continued over the next 10 days.Both Agropyron cristatum and Stipa krylovii's seedling emergence percentage in gaps were far greater than in the controls. All percentageseedling emergence for both species was $>50 \%$, the highest being Stipa krylovii in 40-cm shoot gap treatment with a percent seedling emergence of 74\%. All the percent seedling emergence of Stipa krylovii were more than that in the laboratory. Gap types didn't show a significant impact on the emergence of two grass species $(P=0.077)$, but gap size had a significant effect on percent seedling emergence $(\mathrm{P}<0.001)$.Percent seedling emergence increased as gap areas increased forboth Stipa krylovii and Agropyron cristatum.
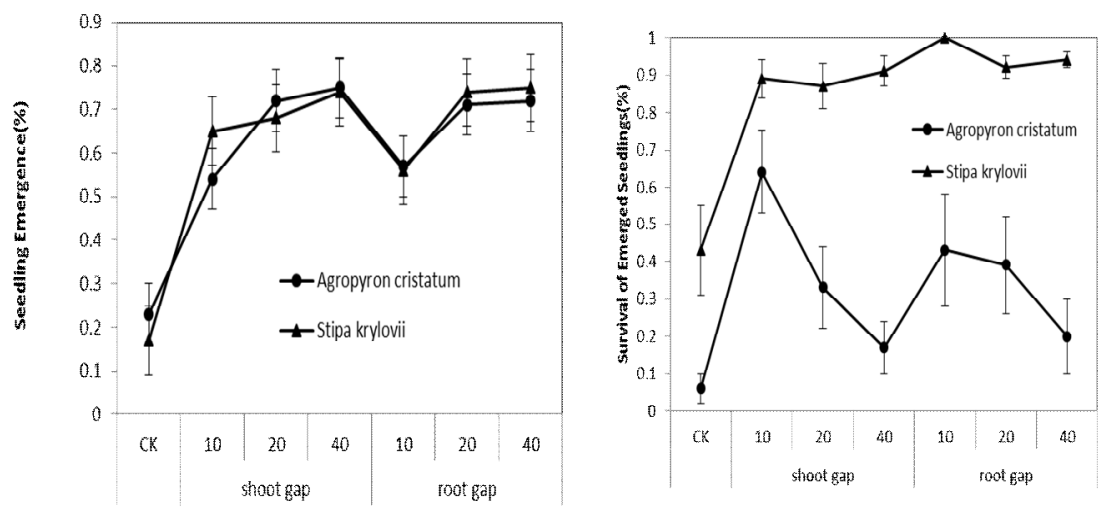

Fig.1.Effects of gap disturbance( including gap size and neighbor root exclusion) on seedling emergence per replicate and seedling survivorship at the end of the growing season ( 90 days from seeding). Bars represent treatment mean \pm SE. Gap size diameters were $10 \mathrm{~cm}(10), 20 \mathrm{~cm}(20)$, $40 \mathrm{~cm}$ (40). Control plots were indicated as CK. 
Both gap size and gap style(shoot gap and root gap) had no significant effects on Stipa krylovii's survival rate. However, although there is not a statistically significant differencein Stipa krylovii, the survival rates of roots gapsare slightly higher than that in shoot gaps.Gap size showed a significantly negative effect on the survival rate of Agropyron cristatum $(P<0.001)$, showing a trend of decreasing survival rate as gaps increased in size. The lowest survival rate of Agropyron cristatum was only $17 \%(40 \mathrm{~cm}$-shoot gap). And also we can see from Fig.1, the survival rate of Stipa kryloviiwas much higher than that of Agropyron cristatum. For Agropyron cristatum, early rates of mortality were similar in all gaps in July, the first month after germination; few seedlings established successfully in any sized gap although Agropyron cristatumhas a relatively high emergence rate.

Table.1. Results of two way ANOVA of seedling performance of Stipa krylovii and Agropyron cristatum

\begin{tabular}{|c|c|c|c|c|c|c|}
\hline \multirow[t]{3}{*}{ variables } & \multicolumn{4}{|c|}{ Sources of effects } & \multicolumn{2}{|c|}{ Interaction } \\
\hline & \multicolumn{2}{|c|}{ Gap style } & \multicolumn{2}{|c|}{ Gap size } & \multirow[b]{2}{*}{$\begin{array}{l}\text { Agropyron } \\
\text { cristatum }\end{array}$} & \multirow[b]{2}{*}{$\begin{array}{l}\text { Stipa } \\
\text { krylovii }\end{array}$} \\
\hline & $\begin{array}{l}\text { Agropyron } \\
\text { cristatum }\end{array}$ & $\begin{array}{l}\text { Stipa } \\
\text { krylovii }\end{array}$ & $\begin{array}{l}\text { Agropyron } \\
\text { cristatum }\end{array}$ & $\begin{array}{l}\text { Stipa } \\
\text { krylovii }\end{array}$ & & \\
\hline Height & $* *$ & $* *$ & $* *$ & $* *$ & $* *$ & $* *$ \\
\hline Tillers & $*$ & $* *$ & $*$ & $* *$ & $*$ & $* *$ \\
\hline $\begin{array}{l}\text { Number of } \\
\text { leaves }\end{array}$ & $* *$ & $* *$ & ns & $* *$ & $* *$ & $* *$ \\
\hline Dry weight & $* *$ & $* *$ & $* *$ & $* *$ & $* *$ & $* *$ \\
\hline
\end{tabular}

Significant effects are indicated by $*=P<0.05, * *=P<0.001$.

Grazing by weevil and invertebrates were found during the early period of seedling establishment for both species, and the grasshopper species Oedaleus asiaticus played the main part of loss of photosynthetic biomass. Predation by these insects accounted for more than $30 \%$ of mortality among seedlings in large gaps in Agropyron cristatum but had no effect in Stipa krylovii. Agropyron cristatum appeared to be more palatable to insects and showed a performance trend of increasing chance of grasshopper herbivory as gap size increased.

\section{Microclimate}

Seasonal changes in soil moisture were similar among each treatment. However, gap size and gap style(shoot gap and root gap) affected soil moisture significantly $(p<0.001, P<0.001)$. Both gap treatments raised soil moisture significantly $(P<0.001)$ compared to the control. Soil moisture increased significantly when rainfall occurred and then decreased quickly. Soil moisture was greatest in the 10-cmroot gap treatmentsand least in the control. The highest soil water content was $30.6 \%$, and the lowest was only $3.75 \%$ in the control. Soil moisture in root gaps was significantlyhigher than that in shoot gaps and controls.

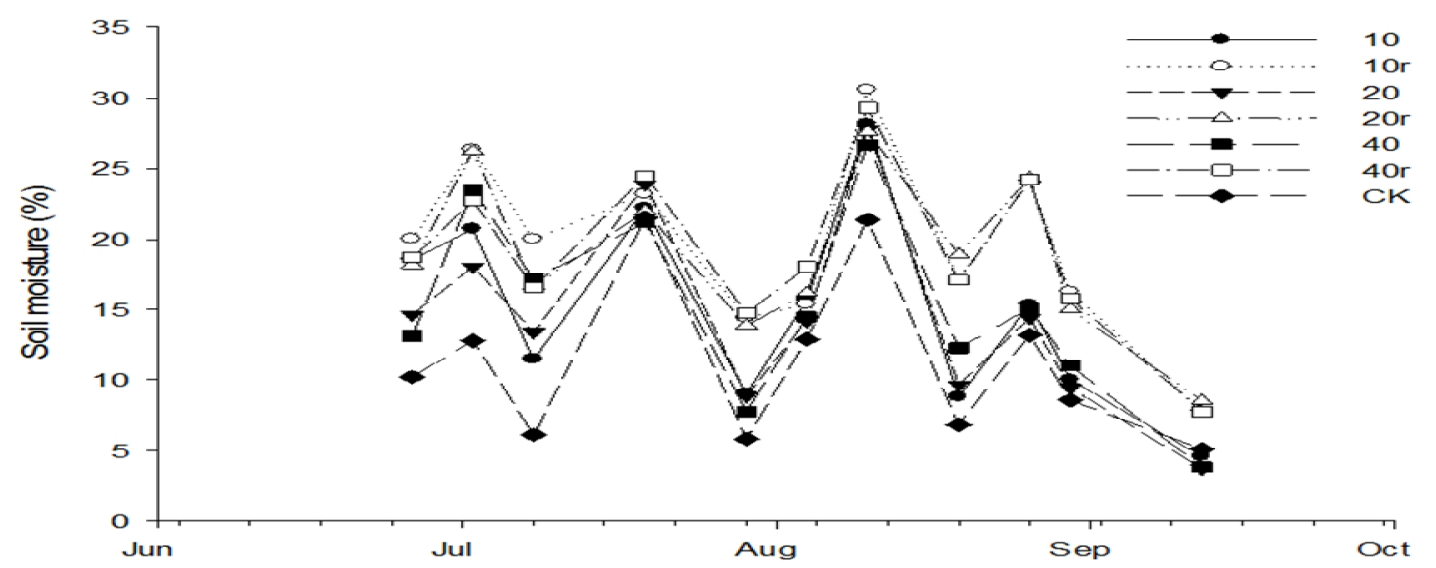

Fig.2. Soil moisture(5-cm depth; means for 5 replicates)dynamics for shoot gap and root gap plots 
through the experiment period. Root gaps were represent by their diameters of $10 \mathrm{~cm}(10 \mathrm{r}), 20 \mathrm{~cm}$ (20r), 40cm (40r).

Two heavy rains were recorded on July $16^{\text {th }}$ andAugust $5^{\text {th }}$. During these events, the soil moisture reached the saturation point.The difference in soil moisture between treatments and control and within treatments was slight. When the grassland sustained a long period of dry weather or the effective precipitation amount was small, especially after the middle of August, soil moisture in the root gap treatment was obviously higher than that of the shoot gap treatment and control.However, the contents show similar decreasing trends(fig.2).

Effects of gap on soil temperature

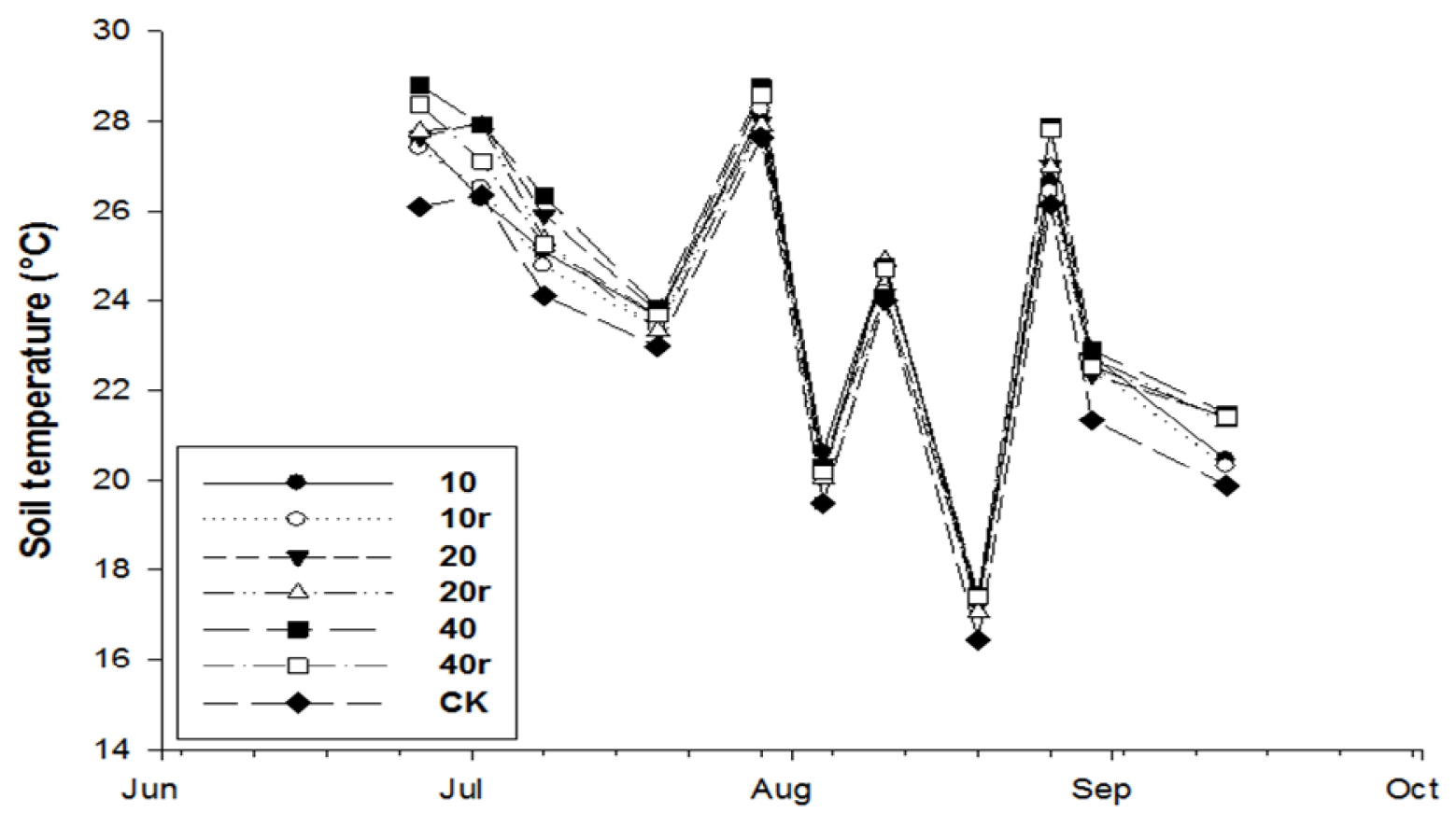

Fig.3.Soil temperature(5-cm depth; means for 5 replicates)dynamics for shoot gap and root gap plots through the experiment period in 2010. Root gaps were represent by their diameters of $10 \mathrm{~cm}$ (10r), $20 \mathrm{~cm}$ (20r), 40cm (40r).

Gap disturbance increased the soil temperatureby $1-2^{\circ} \mathrm{C}$ compared to the controls, but this was not statistically significant.Gap size and gap type have no significant effect on soil moisture respectively $(P=0.416, P=0.464)$. The lowest soil temperature always occurred in the control. Within the same gapsize, soil temperatures of shoot gaps treatments were slightly higher than that of root gap treatments. Highest soil temperature was often in the plots with the largest gap size.

\section{Conclusions}

It was shown that gap size significantly promoted the seedling emergence percentage, the larger the gap area, the higher the emergence of both species.Stipa krylovii's survival rate was significantly higher than that of Agropyron cristatum in all treatments. Both gap size and root exclusion (shoot gap and root gap) had no significant effects on Stipa krylovii's survival rate. However, the survival rate of Agropyron cristatumdecreased significantly with the increase of gap size.The lowest survival rate of Agropyron cristatum was only $17 \%(40 \mathrm{~cm}$-shoot gap).Large gap size increased the chance of Agropyron cristatumseedling predation. Predation by insects was the main limiting factor in the successful seedling establishment of Agropyron cristatum.

Gap size and root exclusion had significantly positive effects on seedling establishment. However, the performance of Agropyron cristatumwas opposite that of Stipa krylovii, it suffered the limitation of new habitat, and its tolerance to predation was worse than that of Stipa krylovii.It's more palatable to grasshoppers and weevils. Selective predation and difference in insects feeding 
tolerance appeared to explain the composition of this community.

\section{Acknowledgements}

Research was funded byBeijng Finance Bureau Science and Technology Innovation Project of "Beijng Monitoring Station of Degraded Ecosystem Restoring in the Long Term Construction (KJCX20140301)" and the Modern Agro-industry Technology Research System (CARS-35), also postdoctoral fund "Effects of Soil Moisture Dynamics on Smooth Brome's Bud Bank". We thank all students and field assistants who helped us with the field work. We thank the Grassland Vegetation Restoration and Reconstruction Key Laboratory for their support.

\section{References}

1. Wagner, M., et al., The germination niches of grassland species targeted for restoration: effects of seed pre-treatments. Seed Science Research, 2011: p. 1-15.

2. Tilman, D. and S. Pacala, The maintenance of species richness in plant communities. Species diversity in ecological communities, 1993: p. 13-25.

3. Aguilera, M.O. and W.K. Lauenroth, Seedling Establishment in Adult Neighborhoods Intraspecific Constraints in the Regeneration of the Bunchgrass Bouteloua-Gracilis. Journal of Ecology, 1993. 81(2): p. 253-261.

4. Liu, G., et al., Effects of adult neighbour and gap size on seedling emergence and early growth of Bromus inermis Leyss. Ecological Research, 2008. 23(1): p. 197-205.

5. Bullock, J.M., et al., Gap Colonization as a Source of Grassland Community Change-Effects of Gap Size and grazing on the Rate and Mode of Colonization By Different Species. Oikos, 1995. 72(2): p. 273-282.

6. Bullock, J.M., Gaps and seedling colonization. Seeds: the ecology of regeneration in plant communities, ed. M. Fenner. 2000: CABI Publishing. 375-395.

7. Pakeman, R.J. and J.L. Small, The role of the seed bank, seed rain and the timing of disturbance in gap regeneration. Journal of Vegetation Science, 2005. 16(1): p. 121-130.

8. Clark, C., et al., Are plant populations seed limited? a critique and meta - analysis of seed addition experiments. The American Naturalist, 2007. 170(1): p. 128-142.

9. Huddleston, R.T. and T.P. Young, Spacing and competition between planted grass plugs and preexisting perennial grasses in a restoration site in Oregon. Restoration Ecology, 2004. 12(4): p. 546-551.

10. Jian, S.U.N., et al., Survival strategy of Stipa krylovii and Agropyron cristatum in typical steppe of Inner Mongolia. Acta Ecologica Sinica, 2011. 31(8).

11. Wang, J.H., et al., Competition between Stipa grandis and Cleistogenes squarrosa. Journal of Arid Environments, 2008. 72(2): p. 63-72.

12. Meng, 1. and H. Gao. Current Situation of Chinese Degraded Grassland and Regeneration Regimes. in China International Grass Industry Development Comference. 2002. China,BeiJing. 